as occur in our existing seas-and this notwithstanding the very different levels at which Pliocene beds now occur Clement REID

\section{EARTHQUAKE-RECORDERS FOR USE IN OBSERVATORIES}

TWO years ago the writer described in NATURE (vol. xxx. pp. 149 and 174) some of the instruments which he had designed and used in Japan for the registration and
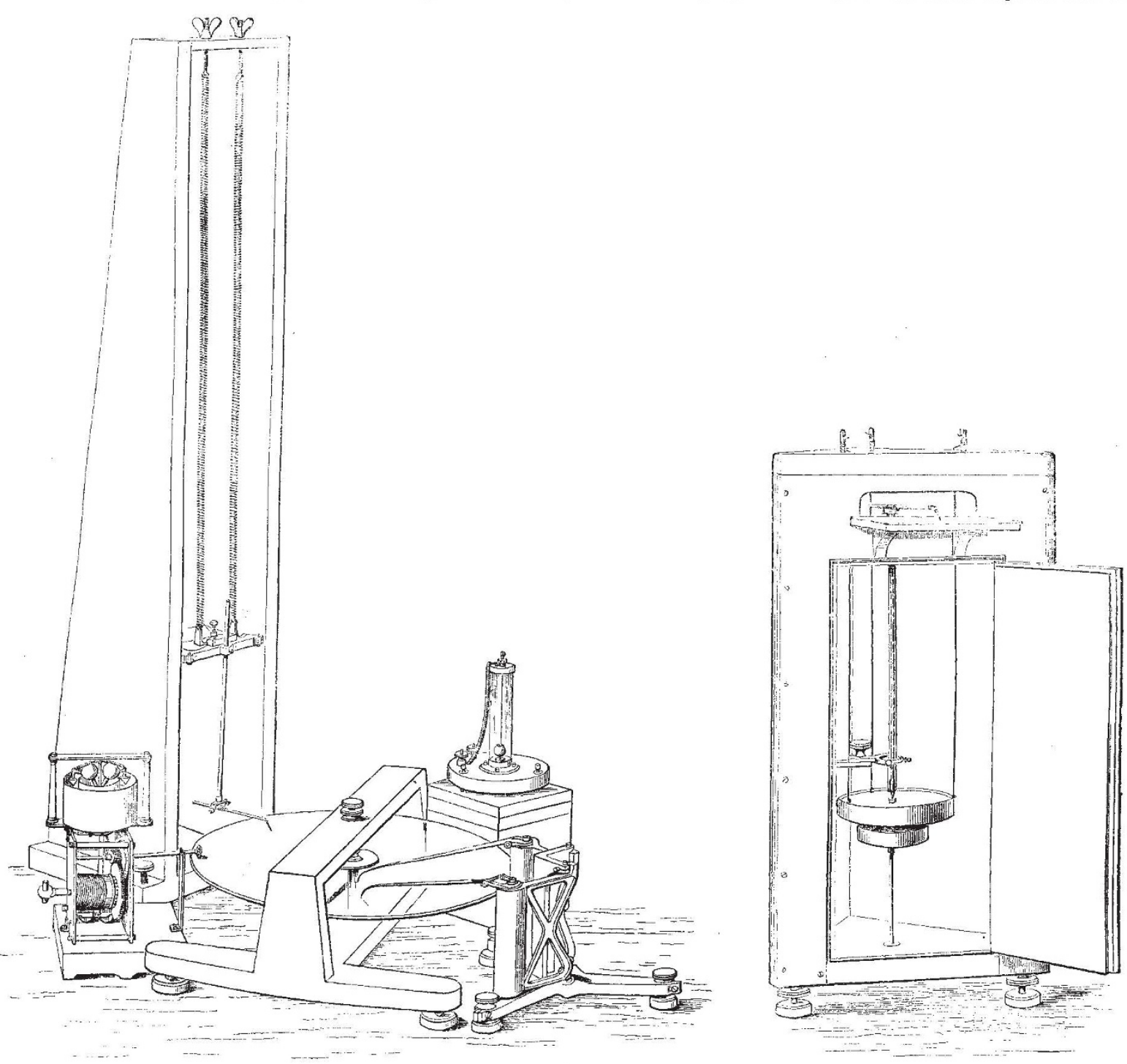

FIG. I.-Complete three-comfonent seismograph, for motions in all direction ..

FiG. 2.-Duplex pendulum seismograph, for horizontal motion. making them easily capable of use by observers who have self-recording, and require little attention during the long intervals which must, in most situations, be expected to elapse between one period of activity and the next.

One group of instruments is arranged to give a complete record of every particular of the movement by resolving it into three rectangular components-one vertical and two horizontal--and registering these by three distinct pointers on a sheet of smoked glass which is made to revolve uniformly by clockwork. A single not made seismometry a special study. They are entirely analysis of earthquake movements. In response to applications from the directors of several observatories, who wished to add seismometric apparatus to their other equipment, arrangements were some time ago made with the Cambridge Scientific Instrument Company for the manufacture of instruments by aid of which the observation of earthquakes might become part of the ordinary work of any meteorological or astronomical station where such movements occasionally occur. In the design of these seismographs the object has been kept in view of earthquake always consists of many successive displacements of the ground; hence the record traced by each pointer on the moving plate is a line comprising many undulations, generally very irregular in character. The amplitude, period, and form of each of these are easily measured, and by compounding the three we obtain full information regarding the direction, extent, velocity, and rate of acceleration of the movement at any epoch in the disturbance.

This group of instruments is shown in Fig. I. In the centre is the plate of smoked glass, which gets its motion 
through a friction-roller from a clock furnished with a centrifugal governor, acting by fluid-friction, and balanced so that its speed is not sensibly affected by the shaking of the ground. The clock is started into motion by means of a Palmieri seismoscope, which appears in the figure behind the plate, on the right. This is a small common pendulum whose bob carries at the bottom a piece of stiff platinum wire that projects into a recess in a cup of mercury below - the recess being formed by an iron pin standing lower than the surface of the surrounding mercury. On the slightest shaking of the ground, contact with the edge of the mercury takes place, and this closes a circuit which releases an electro-magnetic detent and starts the clock. This occurs during the preliminary tremors which are usually found in advance of the main movements of an earthquake. The same circuit starts another clock (of the escapement type) which fulfils two functions. It marks time on the revolving plate during a part of the first revolution, and then continues to go as an ordinary clock, so that, by inspecting its dial afterwards, the interval which has elapsed from the occurrence of the earthquake is known, and the date of the shock in hours and minutes is thus determined with as much precision as the phenomenon admits of. This part of the apparatus is omitted from the figure. The two horizontal components of motion are recorded by a pair of horizontal pendulums, set at right angles to each other, but with their indices inclined so that they write side by side on one radius of the plate. The pen. dulums are supported on a single stand, but with independent adjustments for position and stability. Each has two pivots, consisting of hard steel points, which turn in sapphire centres. At the pivots and at the tracing-points every effort has been made to avoid friction. The indices are of aluminium, and a part of their weight is taken by springs (not shown in the figure), so that their pressure on the plate may be no greater than is necessary to produce a trace on the sooty film. The vertical component of motion is recorded by the instrument which appears behind the clock. A massive bar, free to move vertically about a horizontal axis, is held up by a pair of long spiral springs. Its equilibrium is made nearly neutral by applying the pull of the springs at a suitable distance below the horizontal plane through the axis of support, in the manner described in the article to which reference has already been made. A bell-crank lever with a jointed index gives a multiplied trace of the apparent vertical oscillations of the bar, which correspond to vertical displacements of the ground. In this instrument, as in the others, sapphire centres are used to minimise friction.

Records inscribed on the plate are preserved by varnishing the plate, and using it as a "negative" to print photographs. The motion, as recorded, is magnified to an extent which experience of Japanese earthquakes has shown to be desirable in dealing with disturbances ranging from those which are just recognisable as earthquakes up to those which are to some extent destructive. For great earthquakes, separate apparatus of the same type is designed, in which the multiplying indices are dispensed with, and the scale and style of the other parts are considerably modified.

Another and distinct instrument, also manufactured by the Cambridge Company, is the duplex pendulum seismograph, shown in Fig. 2. A massive bob is hung by three parallel wires from the top of a three-cornered box, and is reduced to nearly neutral equilibrium by being coupled by a ball-and-tube joint to the bob of an inverted pendulum below it. The two form a system which can be made as nearly astatic as is desirable, and so furnish a suitable steady-point for the horizontal part of earthquake movement in any azimuth. The motion is magnified and recorded by a vertical lever geared to the upper bob by a ball-and-tube joint, supported on gimbals from a bracket fixed to the box, and furnished with a jointed index which writes on a fixed plate of smoked glass. Records of the kind which the duplex pendulum gives are of course incomplete in two important particulars: they show nothing of the vertical motion (which, however, is usually a comparatively small part of the whole), and they show nothing of the relation of time to displacement throughout the disturbance. But they exhibit very clearly the change of direction which the movements undergo, and the actual direction taken by any pronounced element of the shock. The writer has recently learnt from his former assistant, Mr. Sekiya, now Professor of Seismology in the University of Tokio, that as many as fifteen of the duplex pendulum seismographs are in use by official and private observers in Japan.

The instrument shown in the figures are now on view at the Edinburgh International Exhibition (Court 2 I, No. 917). Similar sets are being made for the Lick Observatory, California, the Ben Nevis Observatory, and other places. It is scarcely necessary to add that they show the high finish and perfection of workmanship characteristic of the Cambridge Company's manufactures. To Mr. Horace Darwin the writer is especially indebted for a number of suggestions the adoption of which has contributed much to scientific accuracy in details and simplicity in structural arrangements.

\section{J. A. EWING}

\section{THE INSTITUTION OF NAVAL ARCHITECTS} AT LIVERPOOL

THE Institution of Naval Architects departed this year from their almost invariable custom of holding meetings in London, and had a most successful series of meetings at Liverpool. The papers read were few in number, but they were of special, and, in some cases, unusual interest. The meetings were attended by a large number of the Members of the Institution, as well as Liverpool scientific men, shipowners, underwriters, engineers, and others interested in the subjects of discussion. A local paper was read by Mr. G. F. Lyster, C.E., the Engineer to the Mersey Dock and Harbour Board, upon the Docks of Liverpool; Prof. F. Elgar read a paper upon "Losses of Life at Sea "; Mr. B. Martell upon "The Carriage of Petroleum in Bulk on Over-sea Voyages", Mr. W. John upon "Atlantic Steamers"; and Mr. W. Parker on the "Progress and Development of Marine Engineering."

Prof. Elgar's paper upon losses at sea has attracted much attention. It contains a general analysis of the losses that happened during the triennial period that has recently caused so much controversy as to whether loss of life at sea is increasing or not, viz. the three years I $88 \mathrm{I}-83$. Details are given, in a set of tables appended to the paper, of the steamers and iron sailing ships belonging to the United Kingdom, of and above 300 tons gross register, that were reported to the Board of Trade as foundered or missing during the five calendar years I88 $1-85$. The facts contained in these tables show clearly the great advantage it would be to the shipping community if such information were published periodically in a clear and convenient form. Probably no documents that emanate from any Government Department are more bewildering, or more difficult to extract any tangible information from, than the voluminous and complicated returns of wrecks and casualties, and of lives lost at sea, that are published annually by the Board of Trade. We hope that the attention of the Royal Commission now sitting upon Loss of Life at Sea, has been forcibly directed to the many imperfections and the comparative uselessness of the present published returns that profess to deal with these matters ; and that one of the Committee's recommendations will be that something should be done to make them clear and instructive.

There is another cognate matter which we hope will also be dealt with satisfactorily by the Royal Commission, viz. 